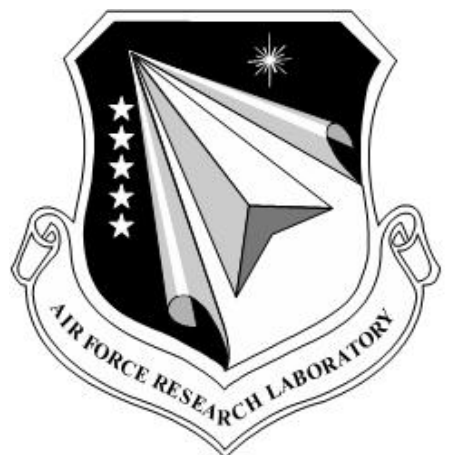

AFRL-HE-AZ-TR-2006-0014

\title{
Competency-based Training: Adapting to Warfighter Needs
}

\author{
Charles M. Colegrove \\ Air Combat Command \\ Flight Operations Division (Alion Science and Technology) \\ Langley Air Force Base VA 23665 \\ Winston Bennett Jr. \\ Air Force Research Laboratory \\ Warfighter Readiness Research Division \\ 6030 South Kent Street \\ Mesa AZ 85212-6061
}

December 2006

Final Report for January 2004 to August 2006

Approved for public release.

Distribution unlimited.
Air Force Research Laboratory
Human Effectiveness Directorate
Warfighter Readiness Research Division 


\section{NOTICES}

This report is published in the interest of scientific and technical information exchange and its publication does not constitute the Government's approval or disapproval of its idea or findings.

Using Government drawings, specifications, or other data included in this document for any purpose other than Government procurement does not in any way obligate the U.S. Government. The fact that the Government formulated or supplied the drawings, specifications, or other data does not license the holder or any other person or corporation; or convey any rights or permission to manufacture, use, or sell any patented invention that may relate to them.

Requestors may obtain copies of this report from the Defense Technical Information Center (DTIC) at http://www.dtic.mil.

The Office of Public Affairs has reviewed this report, and it is releasable to the National Technical Information Service, where it will be available to the general public.

AFRL-HE-AZ-TR-2006-0014 HAS BEEN REVIEWED AND IS APPROVED FOR PUBLICATION IN ACCORDANCE WITH ASSIGNED DISTRIBUTION STATEMENT.

$$
\text { // Signed // }
$$

WINSTON BENNETT JR.

Contract Task Monitor

\section{// Signed //}

DANIEL R. WALKER, Colonel, USAF

Chief, Warfighter Readiness Research Division

Air Force Research Laboratory
// Signed //

HERBERT H. BELL

Technical Advisor 


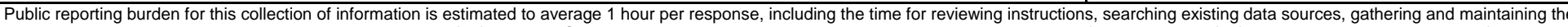

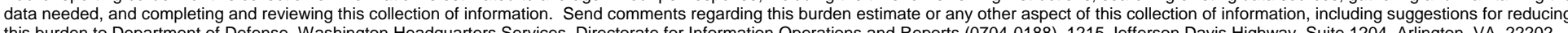

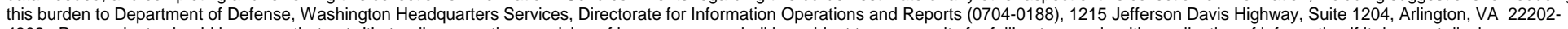

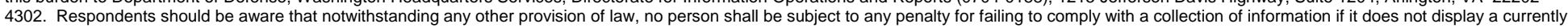
valid OMB control number. PLEASE DO NOT RETURN YOUR FORM TO THE ABOVE ADDRESS.
1. REPORT DATE (DD-MM-YYYY)
2. REPORT TYPE
30-12-2006
Final

\section{TITLE AND SUBTITLE}

Competency-Based Training: Adapting to Warfighter Needs

\section{DATES COVERED (From - To) \\ January 2004 to August 2006 \\ 5a. CONTRACT NUMBER \\ F41624-97-D-5000}

5b. GRANT NUMBER

5c. PROGRAM ELEMENT NUMBER

$27701 \mathrm{~F}$

6. AUTHOR(S)

*Charles M. Colegrove

**Winston Bennett Jr 5d. PROJECT NUMBER

5012

5e. TASK NUMBER

AS

5f. WORK UNIT NUMBER

02

8. PERFORMING ORGANIZATION REPORT NUMBER

10. SPONSOR/MONITOR'S ACRONYM(S)

AFRL; AFRL/HEA

11. SPONSOR/MONITOR'S REPORT NUMBER(S)

AFRL-HE-AZ-TR-2006-0014
*Air Combat Command

Flight Operations Division

(Alion Science and Technology)

Langley Air Force Base VA 23665

9. SPONSORING I MONITORING AGENCY NAME(S) AND ADDRESS(ES)

Air Force Research Laboratory

Human Effectiveness Directorate

Warfighter Readiness Research Division

6030 South Kent Street

Mesa AZ 85212-6061

\section{DISTRIBUTION / AVAILABILITY STATEMENT}

Approved for public release; Distribution unlimited.
**Air Force Research Laboratory Warfighter Readiness Research Division 6030 South Kent Street Mesa AZ 85212-6061

\section{SUPPLEMENTARY NOTES}

\section{ABSTRACT}

Historically USAF Combat Air Forces (CAF) aircrews have trained under an event-based system, maintaining Combat Mission Ready status by accomplishing specified numbers of sortie types and events during the annual training cycle. Advances in training analysis and design and performance measurement are enabling a revolution in training philosophy and a transition to a competency-based training methodology. Competency-based training places emphasis on the required proficiency rather than the number of times the mission has been performed. The transition requires answers to two basic but vital questions; "What do we measure and how do we measure it?" Air Combat Command (ACC) and the US Air Force Research Laboratory (AFRL) have teamed to answer both questions. ACC's Flight Operations Division (ACC/DOT) and the AFRL Warfighter Readiness Research Division, pioneered work in Mission Essential Competencies (MECs - Note that the phrase Mission Essential Competencies, and associated acronyms have been Service Marked.) that provided the "what" - what knowledge and skills do operational aircrew require to succeed in a complex combat environment. MECbased research syllabi and new performance oriented debriefing capabilities have produced dramatic increases in warfighter performance in very short periods of time and are key to answering the "how" question. The implementation of "what" and "how" result in training that is both adaptive to the immediate needs of the training audience and scalable in application from the individual to multi-team collective training. At the end of the day the CAF will season combat aviators quicker and be able to sustain higher levels of overall combat readiness.

\section{SUBJECT TERMS}

Combat mission ready; Competency-based training; MECs; Mission Essential Competencies; Performance measurement; Training analysis and design; Warfighter performance;

16. SECURITY CLASSIFICATION OF:

\begin{tabular}{|l|l|l|}
\hline a. REPORT & b. ABSTRACT \\
UNCLASSIFIED & UNCLASSIFIED & UHIS PAGE \\
& & \\
\hline
\end{tabular}

\section{LIMITATION} OF ABSTRACT

UNLIMITED

\begin{tabular}{|c|l|}
$\begin{array}{c}\text { 18. NUMBER } \\
\text { OF PAGES }\end{array}$ & $\begin{array}{l}\text { 19a. NAME OF RESPONSIBLE PERSON } \\
\text { Dr Winston Bennett Jr }\end{array}$ \\
\cline { 2 - 2 } 14 & $\begin{array}{l}\text { 19b. TELEPHONE NUMBER (include area } \\
\text { code) }\end{array}$
\end{tabular}


This page intentionally left blank. 
COMPETENCY-BASED TRAINING: ADAPTING TO WARFIGHTER NEEDS

\section{EXECUTIVE SUMMARY}

This report describes a revolutionary approach to USAF warfighter training implementation. After a brief introduction and background we describe the concept of Competency-based Training. Next we discuss the major questions that must be answered before this approach can be implemented. Initially the discussion will center on individual training to present the ideas but will later expand to team and inter-team training. In this report "team" refers to a similar group of individuals working together on a common task (e.g., the immediate members of a flight of fighter or bomber aircraft or the mission crew in an Airborne Warning and Control System (AWACS). "Inter-team" and "team-of-teams" refers to collaboration and interactions between teams (e.g., a flight of air-to-air fighters and AWACS or larger package constructs). 
This page intentionally left blank. 


\title{
COMPETENCY-BASED TRAINING: ADAPTING TO WARFIGHTER NEEDS
}

\author{
$\underline{\text { Introduction }}$
}

In 1997 Gen Richard Hawley, Commander of the Air Combat Command (ACC), directed the command to develop and field high-fidelity simulators at individual units and link them together over a wide area network. As the work progressed ACC realized that, for the fighter force in particular, the new simulators, called Mission Training Centers (MTCs), would provide revolutionary training opportunities not normally available in daily flight training or existing simulators. F-15C MTCs were fielded at Langley and Eglin AFBs on the expectation that "if we build it, they will come.” That speculation proved to be correct when the pilots at those bases started using the MTCs at twice the rate specified by training regulations. ACC had incorporated the term Mission Essential Competency (MEC) ${ }^{\mathrm{SMi}}$ in the CONOPS for the command's Distributed Mission Operations (DMO) program. In 2000 ACC, in partnership with the Air Force Research Laboratory's Warfighter Readiness Research Division (AFRL/HEA), embarked on a program to optimize the use of advanced simulation in aircrew training programs. As part of that program the team devised the MEC methodology (Colegrove \& Alliger, 2002). Advanced technologies and training strategies developed as part of ACC's DMO program will have a global application through all warfighter training methods and media.

\section{The Ready Aircrew Program ${ }^{[i i]}$}

The Ready Aircrew Program (RAP) was instituted in 1997 as a result of a Chief of Staff USAF (CSAF) directive to improve the process for determining aircrew flying hour requirements. As a result ACC developed RAP to remedy several shortfalls of the previous Graduated Combat Capability training system. In addition to the CSAF requirements, ACC added the intent to improve the overall quality of training, defend and allocate resources necessary to conduct training programs, and improve the link between warfighter training and readiness reporting (Henry, 1997).

The training technologies available prior to the advancements made in conjunction with DMO limited RAP to a sortie- and event-based training and tracking system. Each aircrew, based on a 500 -flying hour benchmark, is ranked as inexperienced $(<500$ hours in the aircraft) or experienced (500 hours or more). Inexperienced F-15C pilots, for example, are required a minimum of 18 Defensive Counter Air (DCA) missions on a 12-month basis. Experienced pilots are required a minimum of 14 DCA missions during the same period. Events are activities within a sortie such as chaff and flare employment. The numbers and types of sorties, and events within sorties, required for "proficiency" has been developed through many years of experience and deficiency analysis.

\footnotetext{
i The phrase "Mission Essential Competency," "Mission Essential Competencies," and associated acronyms have been Service Marked. The superscript (SM) symbol only appears once at the first instance of each example.

[ii] The Ready Aircrew Program has been realigned to USAF Air and Space Expeditionary Force cycles and is now a 20-month training specification. For clarity this report uses a 12-month period of training.
} 
RAP, on balance, has been an effective system for training today's USAF warfighters. It provides the justification for flying hour requirements and associated training resources. Shortfalls inherent to the RAP system can be addressed using new technologies and training strategies.

In a sortie-based training system, proficiency, ranging from that of the individual through the team or team-of-teams, is left to subjective assessment. There is no requirement for the inexperienced F-15C pilot to "survive" all 18 DCA missions. Accomplishing the 18 sortie requirement fills the training obligation and maintains Combat Mission Ready (CMR) status. Continued CMR status is not dependent on sustained proficiency and individuals may retain combat mission ready status even though they have a higher than average "mortality rate" in the course of those 18 DCA missions. Astute squadron leadership should notice that the individual "died" on an inordinate number of the missions and take corrective action but there is no current method to consistently analyze and correct deficiencies nor is there a standard that measures survivability against mission complexity.

RAP training specifications are a "one size fits all". Sortie and event requirements are minimums but all inexperienced F-15C pilots require at least 18 DCA missions during the year. Due to competition for scarce training resources there are times when necessary training over and above the minimum must give way to higher priorities. Then the minimum number of sorties becomes the maximum.

Competency-based training, while based on a core number of live and simulated training sessions, will retain the best of the Ready Aircrew Program while providing adaptive training based on the needs of the training audience. The operational community has the opportunity to leverage ongoing research and development to begin a phased implementation of competencybased training.

\section{What is Competency-based Training?}

"Competency-based Training is the ability to compare individual aircrew performance to a defined proficiency level, maintain acceptable levels of performance and target areas requiring improvement." (Colegrove, 2004)

As previously discussed, traditional training methods concentrate on the number of times the aircrew is exposed to a training event that replicates, with varying degrees of accuracy, the combat environment. Competency-based training focuses on mission performance rather than mission type. The design of the training system will retain training accountability and the justification for training resources. Most importantly, competency-based training does not remove the responsibility of commanders, supervisors, and instructors to train personnel under their command. Assessment tools oriented to measuring and tracking performance will enable more efficient post mission analysis and review by providing detailed information on "what happened" thereby allowing those responsible for the learning outcome to concentrate on the "why." 
Competency-based training provides a seamless stream of consistent performance data regardless of the live or virtual training methods. The ability to measure performance against standards established by the user community not only provides control by the operational community but also defines consistent measurement criteria across a single weapon system at multiple bases. While the initial implementation will be applicable for local training, the concept is expandable for sensor-shooter training and to Air Operations Center (AOC) and Air and Space Expeditionary Force (AEF) certification. The beta version of the technology has been used in Exercise First WAVE (Warfighter Alliance in a Virtual Environment).

\section{Why Should We Transition?}

Advances in training technology now allow us to concentrate training on performance. We now have the ability to highly instrument training ranges and record, in minute detail, precise movement and exact timing during complex combat sequences. Integration of complex avionics provide new opportunities for on- and off-board data logging that can record avionics management, sensor control, and weapons employment.

Research conducted by AFRL/HEA using MEC-based air-to-air syllabi and performance oriented post-mission analyses has produced the following results:

- Assessments with 21 teams / 84 CMR F-16 pilots

- $63 \%$ fewer enemy bombers reached their target

- $24 \%$ more enemy fighter aircraft killed

- $68 \%$ fewer F-16 mortalities

- $63 \%$ less time spent in enemy threat envelopes

- Validated training methodology and objective measurement

\section{$\underline{\text { Two Important Questions }}$}

The Mission Essential Competency structure encompasses knowledge, skills (KS) and developmental experiences (Colegrove, 2005). AFRL/HEA has developed a methodology to link these experiences to the KS they support and then directly to the higher level MEC (Symons, France, Bell, \& Bennett, 2005). MECs answer the question, "What do we measure?"

The second question involves the method of measurement or "How do we measure what we've decided to measure?” Again, ACC and AFRL/HEA have partnered. In 2004 ACC sponsored an HEA proposed Advanced Technology Demonstration (ATD) involving performance measurement and tracking. This ATD, the Warfighter Readiness Assessment - Performance Measurement Tracking System (WRA-PMTS), will form the nucleus of the transition to competency-based training. 


\section{$\underline{\text { Setting the Bar }}$}

The "bar," that is, the performance required in combat, is provided by the MECs which are defined as:

"Higher-order individual, team, and inter-team competencies that a fully prepared pilot, crew or flight requires for successful mission completion under adverse conditions and in a nonpermissive environment."

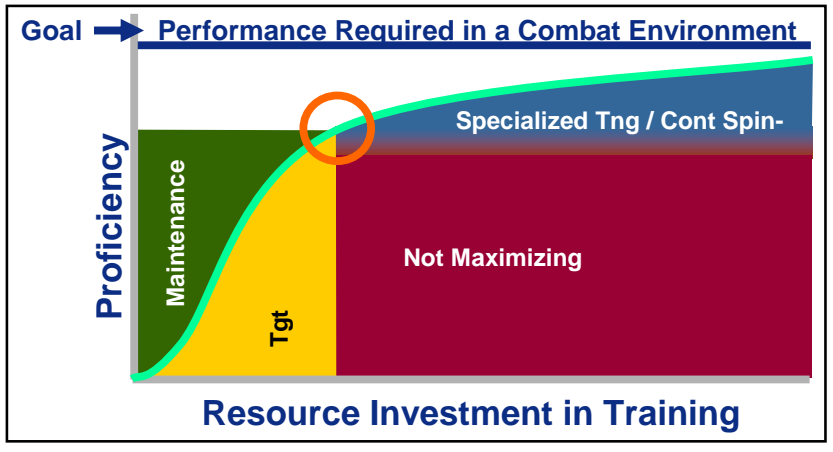

Figure 1: Example generic learning curve

The curve in Figure 1 (the light green line) is actually comprised of several curves that represent proficiency at the individual, flight or crew, package, and large force levels (Chatham \& Braddock, 2005). For the initial discussion we will use individual proficiency to explain the concept then expand to larger composite or collective training audiences.

The key in this training definition is the application of the adverse, non-permissive environment, combat, as the condition under which real-world performance is carried out and assessed. The horizontal scale is labeled Resource Investment in Training. It can also represent the timeline of an individual's career or progression in a weapon system. Proficiency (competency) is measured in the vertical. The learning curve is sinusoidal in nature and, after rapid improvement at the novice level, eventually reaches a point of diminishing returns - the point where even large applications of resources produce progressively smaller gains in proficiency.

The desired position on the curve is the "knee" indicated by the red circle. The knee defines the optimum combination of performance and training resource investment. This point and all points on the curve, whether for an individual weapon system, a sensor-shooter team, or larger package, are yet to be defined by the operational community but will be required to affect the transition. The curve establishes individualized expectations of performance based on the maturity level of the individual, team or team-of-teams warfighting entity. For example, proficiency standards for four-ship flight leaders would not be the same as for non-leads nor would the expectations for entry level air battle managers be the same as for the Senior Director on an AWACS Mission Crew. Newly formed sensor-shooter teams would start at the left side of the graph and progress upward in proficiency through applied collaborative training. AEFs 
rarely have the opportunity to train together as a composite, or collective, force and during latter phases in the AEF training cycle when composite training does occur can be expected to enter the composite learning curve to the left of the knee. To maximize effectiveness, composite training requires the individual teams, and individuals, bring a degree of proficiency in their mission areas and specialties.

The area around the curve is divided into two main areas of interest and each main area is further subdivided into two sub areas. For the purpose of this discussion the area to the right of the knee and above the flat section of the curve, while highly desirable, is not a generally sustainable level of proficiency.

\section{Lines and Quadrants}

An important aspect of the competency-based construct is the fact that the operationally developed standards may be very specific while the width of the learning curve is actually defined by performance boundaries. These boundaries are designed to accommodate occasional moments of brilliance and less than perfect performance without disturbing the entity's position on the Proficiency/Resource matrix. For the purpose of debriefing today's training event, competency-based training must be able to highlight today's accomplishments or lack thereof. Forecasting future training needs requires tracking and analyzing trend information.

For all practical purposes no warfighting entity will always fall within the boundaries defining the curve. Most of the time for that entity will be spent maintaining skills and knowledge that meets or exceeds standards or applying training specifically designed to correct downward trends.

The sub area to the left of the steep part of the curve labeled "Maintenance" is the most desirable area. Performance in this area meets or exceeds expectations and is the area where proficiency is most easily maintained. Operators require less frequent exposure to those skills and environments where they have a high degree of competency. If applied at the correct time and intensity, training resources can be optimized to maintain skill and knowledge levels. The maintenance mode will be driven by the results of skill retention and decay studies as well as the ability to detect small downward trends in proficiency within the maintenance area.

Performance or demonstrated knowledge that does not meet standard expectations can have several causes. Novitiates, including skilled performers involved in novel situations, initially tend to have a flatter learning curve until "the light bulb comes on.” At that point learning and performance usually increase rapidly in response to nominal resource investment. Substandard performance may also be caused by intentional or unintentional neglect. Real-world constraints may deny the ability to provide experiences necessary to maintain proficiency in critical skills. A very promising way to mitigate this influence is the ability to precisely control scenario elements and mission complexity in virtual training events. Unintentional skill decay results from interruptions in training due to illness, non-flying temporary duties, or possibly contingency operations that do not provide an experience-rich environment. In either case, if the layoff is long enough, the warfighter must reestablish his or her position relative to the curve and trainers must provide those training experiences and resources that will generate the most rapid 
recovery. MEC analyses identify the most important experiences necessary to develop proficiency in mission-level tasks. Training planners can use these experiences to design and monitor the most expeditious path.

The large area to the right of and below the knee is an area to be avoided. Large expenditures of resources will not transform an underachiever into an expert warfighter more efficiently than the ability to specifically target weak areas. Sending a novice pilot that is still in training to resource rich Red Flag could cause a regression due to a high probability of constant task saturation.

The area to the right of the knee and just below the curve is a justifiably necessary expenditure of intense training resource environments. This is the area in which we produce USAF Weapons School graduates and prepare for very specific contingency operations. Heretofore this area has been dominated by live training and very labor-intensive analysis and reconstruction. Advances in virtual training technology have already begun to pay dividends in high-end training.

\section{Daily Use}

In practice, the trainee attends a training event. During the event instrumentation provides a recording of performance parameters that are based on skills that have been targeted for that event and can be compared to a standard performance in the debrief.

One of the air-to-air MECs is "Intercepts and targets factor groups." "Manages offensive and defensive weapons engagement zones (WEZ) properly" is an associated Supporting Competency (SC) and one of the skills required for proficiency is "Controls intercept geometry." A performance metric used to determine how well the pilot controls the intercept is the amount of time spent in an adversary's engagement zone. The ability to track, over time, the pilot's ability to minimize exposure is an indicator of proficiency. Note the performance tracking system reports the amount of time in the WEZ and, if desired, can compare that time to a standard. However, the system does not analyze the rationale for entering the WEZ. The pilot may have a good reason to do so and that analysis is left to the instructor.

Initially each pilot would accomplish a standardized core set of live and virtual missions. The intent is to build performance profiles and benchmark the applicable skills, the summaries of which provide the position on the Proficiency/Resource Investment learning curve.

After the initial position is established the pilot enters the adaptive Maintenance/Targeted Training mode - maintaining those skills that meet or exceed standards and using the most efficient training media to execute customized training. Extended periods without flying require another series of core missions to re-benchmark. A centralized performance tracking system will make recommendations for the next training activity based on identified weak areas and the "best value" training media. 


\section{Implementation}

The transition to competency-based training requires a phased approach. In the near term, MECbased syllabi designed for simulation training will develop proficiency sooner and more efficiently. Properly structured virtual training, applied when a unit member first arrives, has shown, in a small sample size, to accelerate those individuals ahead of their peers. As a quick example, AFRL Mesa designed a short virtual combat training syllabus of 2 versus 2 and 2 versus 4 tactical scenarios, based on identified knowledge, skills and experiences, for pilots who were graduating from their Field Training Unit (FTU) and moving to their first operational posting. The goal of this quick look was to assess the likely impact of a principled, competencybased virtual training exposure on knowledge and skills identified as important for new combat pilots to possess.

Our results, which are based on a very small sample of six pilots, indicate that the graduates who were exposed to our competency-based scenarios benefited substantially from the virtual training exposure. When compared to a cohort of six pilots who graduated in the same timeframe and were posted to a base with the same aircraft, the virtual trained pilots were rated by their new organizations as being substantially better at flight planning, maintaining communications standards, and working as wingmen. A more comprehensive study of these effects is planned.

Finally, the results from this quick look have also pointed to the potential for developing a set of more fundamental or foundational knowledge and skills that could help to not only restructure how school house combat training is accomplished, but also to define the relationships and linkages from knowledge and skill proficiency in school to proficiency in the first posting after school.

From the operational implementation of competency-based training perspective, our goals for the near-term involve redefining aircrew experience, currently expressed in the number of hours in the aircraft, in terms of knowledge and skill and addressing identified training gaps with validated, standardized scenarios, syllabi, and tools. MECs will be used to steepen the learning curve at specified points in the training continuum and reassign training methods and media to achieve the biggest bang for the resource investment. The first steps of this phase have already begun with the reallocation of RAP training requirements to high-fidelity simulators in the F15C community.

Intermediate implementation is designed to integrate live and virtual training to build on the steeper learning curve from the initial phase. This phase requires performance metrics and feedback mechanisms that are common between live and virtual training. This consistency throughout the training environment is independent of the method or media to facilitate definition of retraining intervals and content.

At the end state, competency-based training will sustain the highest practical level of proficiency through targeted, effects-based training. Each training method will be accredited for the value it brings to developing and maintaining the proficiency of individual warfighter, team, and teamof-teams. The system will be able to analyze today's training and develop recommendations for tomorrow's training events that are adapted specifically to the needs of the training audience. 
The appropriate level of training complexity - size and composition of friendly forces, numbers and mix of adversary forces, and benign/adverse operating environments - will be generated on demand to develop proficiency in specific operational capabilities.

\section{Training Strategies and Technologies}

The MEC structure at Figure 2 shows the decomposability between the MECs, SCs, Skills/ Knowledge, and the experiences necessary to develop the proficiency at all the MEC levels.

MECs are scalable from individuals to teams and team-of-teams. Air-to-air and AWACS aircrew have a MEC related to detection, an activity in which they must collaboratively succeed to be successful in a combat environment. Drawing on that commonality we can design objectives for sensor-shooter training that emphasize the skills and knowledge associated with each team's portion of the mission as well as provide an organizing structure for the combined team-of-teams.

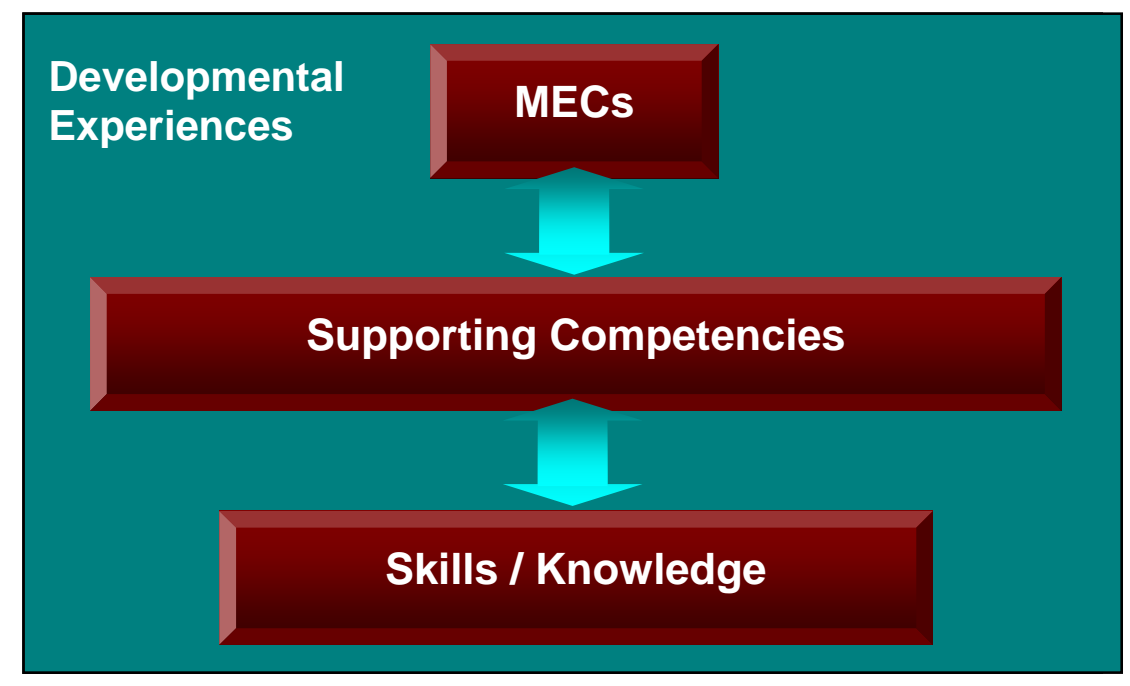

Figure 2: The general relationship amongst MEC components

A primary purpose of performance measurement is to identify strengths and weaknesses in the knowledge and skills necessary for successful air combat so that training can be focused on addressing identified MEC deficiencies. Assessing knowledge and skill proficiencies based on performance data can be thought of as assigning "credit or blame" to a knowledge or skill element or combination of elements for observed performance deficiencies. The goal is to develop individual and team competency profiles based on performance over a single DMO exercise and a series of DMO exercises. The competency profiles can then be used to track progress and tailor exercises based on individual and team mastery or lack of mastery of specific competency areas (Bennett, Schreiber, \& Andrews, 2002). 
Data gathering and performance measuring systems will able to track and record track sensor coverage, communication flow and content, and time from detection to engagement. Data, at any desired level of specificity, will be available for post-mission analysis and evaluation.

This evaluation process combines objective performance information automatically generated using training simulation data files with performance information generated by instructor/observers. Another potential source of information to support competency assessments is data provided by the pilots themselves, either during debrief or through postexercise questionnaires. This source of information may be particularly useful in assessing knowledge competencies. A range of knowledge and skills combine to produce effective performance in any MEC area. Objective simulation-based measures and observation-based measures together provide a rich basis for assessment of the knowledge and skills that support each MEC. By using a common measurement framework, observation- and simulation-based data can be integrated to provide assessments at the knowledge, skill, and MEC level.

\section{Conclusion}

Competency-based training offers unique applications and opportunities to enhance warfighter training. While much work remains to be done the major components have been identified and significant progress is being made in completing the MECs for each weapon system and developing the technology necessary to reliably and consistently conduct the measurement and record the data.

Structured, MEC-based training has been proven at the individual and team level. The way ahead includes expanding the MECs to encompass team-of-teams collaborative warfighting activities and institutionalizing the MEC hierarchy in daily training.

As fiscal constraints become more important in daily training, competency-based training offers the ability to optimize training resource allocation while maintaining warfighter readiness and operational capability. 


\section{$\underline{\text { References }}$}

Bennett, W., Jr., Schreiber, B.T., \& Andrews, D.H. (2002). Developing competency-based methods for near-real-time air combat problem solving assessment. Computers in Human Behavior, 18 (773-782).

Colegrove, C. \& Alliger, G. (2002). Mission essential competencies: Defining combat mission readiness in a novel way, Presented at the SAS-038 Symposium, Brussels Belgium.

Colegrove, C. (2004). Competency-based training, Presented the Combat Air Forces Distributed Mission Operations Users’ Conference

Colegrove, C. (2005) Mission Essential Competencies: The operational application of today's training analysis for tomorrow's Advanced Distributed Training. Presented at the RAeS Conference: Multi Role And Networked Simulation

Henry, L. (1997). A primer for the Ready Aircrew Program (RAP).

Symons, S., France, M., Bell, J., \& Bennett, W., Jr. (2005). Linking knowledge and skills to Mission Essential Competency-based syllabus development for Distributed Mission Operations (AFRL-HE-AZ-TR-2006-0041, ADA453737). Mesa AZ: Air Force Research Laboratory, Warfighter Readiness Research Division.

Chatham, R. \& Braddock, J. (2005). Training superiority and training surprise - Final Report, Defense Science Board Task Force. Accessed 30 August 06 at http://www.dtic.mil/ndia/2001testing/chatham.pdf 